\title{
Smoking is associated with an age-related decline in exhaled nitric oxide
}

\author{
J.S. Sundy*\#, D.W. Hauswirth ${ }^{\star}$, S. Mervin-Blake*, C.A. Fernandez*, K.B. Patch*, \\ K.M. Alexander*, S. Allgood*, P.D. McNair* and M.C. Levesque*
}

ABSTRACT: Age-related declines in forced expiratory volume in one second are accelerated in smokers. Smoking is associated with decreased exhaled nitric oxide fraction ( $\mathrm{FeNO})$. The aim of the present study was to determine the impact of age on FeNO in otherwise healthy smokers and nonsmokers.

FeNO and serum cotinine levels were measured in 994 healthy subjects aged 18-40 yrs. American Thoracic Society questionnaire data on smoking habits was used to validate serum cotinine levels as a surrogate marker for categorisation of smokers and nonsmokers in the cohort.

Serum cotinine levels were a good discriminator of smokers $(n=99)$ and nonsmokers $(n=895)$. FeNO levels were significantly lower in otherwise healthy smokers compared with nonsmokers. There was an inverse correlation of serum cotinine levels with FeNO. No correlation of age with $F \mathrm{eNO}$ was found in nonsmokers but an inverse correlation of $F \mathrm{eNO}$ with age in smokers was found. FeNO was significantly lower in smokers aged 21-40 yrs compared with nonsmokers aged 21-40 yrs, but was not lower in smokers aged 18-20 yrs compared with nonsmokers of the same age.

Smoking was associated with decreased exhaled nitric oxide. The greatest smoking-related declines in exhaled nitric oxide occurred in older subjects. This suggests that smoking is associated with age-related declines in exhaled nitric oxide and justifies future mechanistic studies that address the impact of exhaled nitric oxide decline on lung function.

KEYWORDS: Ageing, humans, nitric oxide, smoking

nhaled tobacco smoke has acute and chronic effects on exhaled nitric oxide fraction $(\mathrm{FeNO})$.

FeNO levels are lower in otherwise healthy subjects who habitually smoke tobacco compared with nonsmokers [1-8], and FeNO levels decrease in nonsmokers and smokers acutely after smoking a cigarette and after passive smoke exposure $[1,5,9]$. There is an inverse relationship between the number of cigarettes smoked per day and FeNO levels [1]. FeNO levels increase after smoking cessation but not to normal levels $[2,6,10]$, which suggests that smoking-related declines in FeNO may be associated with permanent lung damage. As respiratory epithelium is the likely source of most FeNO [11-15] and is damaged by chronic smoke exposure [16-20], smoking-related declines in FeNO may be a marker of airway epithelial damage.

There are several reasons to believe that low FeNO levels in smokers may be detrimental. Ageing is associated with declines in lung function and agerelated declines in lung function are accelerated in smokers [21, 22]. Smoking-related declines in forced expiratory volume in one second (FEV1) with increasing age are important determinants of obstructive lung disease [23, 24]. Nitric oxide (NO) promotes bronchodilation [25-28] and, as such, smoking-related declines in FeNO may contribute to bronchospasm or obstructive lung disease in smokers. NO is also important in resistance to infection $[29,30]$ and decreased FeNO may predispose to respiratory infection.

If smoking-related declines in FeNO were associated with respiratory epithelial damage, then otherwise healthy older smokers should have lower FeNO levels than younger smokers. Prior studies of $F$ eNO in nonsmoking adults indicated that there was no association of age with FeNO levels [31]. In a recent study, MCSHARRY et al. [32] identified an association of decreasing FeNO levels with age in asthmatic smokers. Whether smoking results in age-related declines in FeNO in otherwise healthy subjects has not been determined.

Therefore, a secondary analysis was performed of a large cohort of otherwise healthy AfricanAmerican smokers and nonsmokers who participated in a genetic study of lung function and FeNO to determine the effect of age on FeNO
AFFILIATIONS

*Dept of Medicine, Division of Rheumatology and Immunology, \#Division of Pulmonary, Allergy and Critical Care Medicine, and 'Dept of Paediatrics, Division of Allergy and Immunology, Duke University Medical Center, Durham, NC, USA.

CORRESPONDENCE

M.C. Levesque

Duke University Medical Center Box 3266

Durham

NC 27710

USA

Fax: 19196844141

E-mail: marc.levesque@duke.edu

Received:

July 122007

Accepted after revision:

September 172007

SUPPORT STATEMENT

The study was funded by the Sandler Program for Asthma Research (San Francisco, CA, USA), the National Institute of Environmental Health Sciences (ES011185; Research Triangle Park, NC, USA), and the National Center for Research Resources, Clinical Research Centers Program, National Institutes of Health (M01-RR-30; Bethesda, MD, USA)

STATEMENT OF INTEREST

None declared.

European Respiratory Journal

Print ISSN 0903-1936

Online ISSN 1399-3003 
levels. The current authors found that smoking-related declines in FeNO are greatest in older subjects. This suggests that smoking is associated with age-related declines in FeNO and justifies future mechanistic studies that address the impact of FeNO decline on lung function.

\section{METHODS}

\section{Subject recruitment and enrolment}

The present study results represent a secondary analysis of data obtained from subjects who were recruited as part of a study of the relationship between FeNO and type II inducible NO synthase (NOS2) genotypes present in African-Americans [33]. Healthy subjects aged $18-40$ yrs were recruited from students and employees at local university campuses. In total, 994 subjects with adequate serum samples and FeNO levels were available for analysis. Informed consent was obtained as part of a protocol approved by the Duke University Institutional Review Board (Durham, NC, USA).

After giving informed consent, subjects were asked to provide their date of birth and declare that they were healthy (i.e. no chronic illnesses or chronic use of any medication except oral contraceptives), that they had no history of asthma, allergic rhinitis, hay fever or atopic dermatitis, that they were nonsmokers, and that they were of African ancestry. Ethnicity was based on a self-declared description of ethnicity and determined using a questionnaire based on that developed by the US Census bureau. Blood samples for preparation of serum were obtained. FeNO was measured and a modified American Thoracic Society (ATS) questionnaire [34] was also administered to 524 subjects at the time of enrolment. The modified questionnaire collected information on smoking, cough, phlegm production, wheezing, dyspnoea and asthma history. The questionnaire also collected information about rhinitis, eczema and other allergy symptoms.

\section{Measurement of FeNO}

FeNO levels were measured in triplicate and averaged using a Sievers 280i Nitric Oxide Analyzer (NOA; GE Analytical Instruments, Boulder, CO, USA) according to the manufacturer's instructions. FeNO was measured according to ATS recommendations [35] at a flow rate of $50 \mathrm{~mL} \cdot \mathrm{s}^{-1}$ and against enough resistance to maintain an oropharyngeal pressure of $\geqslant 5 \mathrm{cmH}_{2} \mathrm{O}$ and thereby permit closure of the soft palate and exclusion of nasal NO. Ambient air NO was excluded by inclusion of an activated charcoal and potassium hydroxide filter unit attached to the air intake of the NOA flow meter. Subjects were asked to breathe at least three times through the NOA flow meter with the attached activated charcoal and potassium hydroxide filter unit to reduce airway NO from ambient air prior to each FeNO measurement.

\section{Serum total immunoglobulin E level measurements}

Total serum immunoglobulin (Ig)E levels were measured using the Pharmacia CAP System (IgE FEIA; Pharmacia Diagnostics, Uppsala, Sweden).

\section{Serum cotinine levels}

Serum cotinine levels were determined using an ELISA-based assay from OraSure Technologies (Bethlehem, PA, USA). Manufacturer-specified cut-points for serum cotinine levels were used to separate subjects into smokers $\left(\geqslant 25 \mathrm{ng} \cdot \mathrm{mL}^{-1}\right)$ and nonsmokers $\left(<25 \mathrm{ng} \cdot \mathrm{mL}^{-1}\right)$.

\section{Statistical analysis}

Continuous variables (age, FeNO, total IgE, eosinophil cationic protein (ECP) and C-reactive protein (CRP) levels) were not normally distributed and were log normalised prior to statistical analysis. For the comparison of FeNO levels in subjects with different cotinine levels, ANOVA testing was used with multiple pairwise comparisons using Tukey-Kramer tests. For the linear regression analysis of cotinine levels and FeNO levels, cotinine levels were log normalised to permit a parametric analysis. For the analysis of current smokers and subjects that denied being ever smokers, cotinine levels were not log normalised because many cotinine levels were $0 \mathrm{ng} \cdot \mathrm{mL}^{-1}$. In this analysis, cotinine levels were not normally distributed and nonparametric statistics (Wilcoxon rank-sum test) were used for this analysis. For univariate analyses of FeNO levels, unpaired t-tests were used for comparisons of smokers and nonsmokers. Subjects were dichotomised into younger (18-20 yrs) and older (21-40 yrs) groups based on the median age (20 yrs) of the cohort. Pearson's product-moment correlation coefficient was used for linear regression analyses of FeNO levels versus age and serum cotinine levels. Multiple linear regression was used for comparisons of FeNO levels while controlling for age, smoking status, sex, cotinine and total $\mathrm{IgE}$ levels. There were no corrections for multiple testing and the reported $\mathrm{r}^{2}$ values were unadjusted.

\section{RESULTS}

\section{Association of elevated cotinine levels with self-reported current cigarette smoking}

The present authors' original a priori study of genetic correlates of FeNO levels was designed to exclude smokers. However, given the significant association of cigarette smoking with lower FeNO levels [1-8], ATS questionnaire data on smoking [34] were collected and serum cotinine levels were measured $[36,37]$ as a way to rigorously exclude smoking as a potential confounder of FeNO levels. To confirm the validity of using serum cotinine levels as a surrogate marker of cigarette smoking, cotinine levels were compared in subjects who selfreported cigarette smoking on the ATS questionnaire with subjects that did not report smoking. Of the 524 subjects who were administered ATS questionnaires, seven reported being current smokers and 471 denied being ever-smokers (i.e. subjects who reported being either current smokers or past smokers). Cotinine levels were higher in subjects who reported being current smokers versus subjects that denied being eversmokers (median (interquartile range) $29.4 \mathrm{ng} \cdot \mathrm{mL}^{-1}(0.3-$ $\left.130 \mathrm{ng} \cdot \mathrm{mL}^{-1}\right)$ versus $0.1 \mathrm{ng} \cdot \mathrm{mL}^{-1}\left(0-0.6 \mathrm{ng} \cdot \mathrm{mL}^{-1}\right) ; \mathrm{p}=0.0025$, Wilcoxon rank-sum test). This analysis confirmed previous reports and validated the use of cotinine levels as a surrogate for cigarette smoking in the present cohort of subjects.

The manufacturer of the serum cotinine assay used in the present study recommends a cut-off of $25 \mathrm{ng} \cdot \mathrm{mL}^{-1}$ for the identification of smokers. The current authors found that, despite self-reporting of nonsmoking by many subjects, 99 $(10 \%)$ subjects had elevated serum cotinine levels $\left(\geqslant 25 \mathrm{ng} \cdot \mathrm{mL}^{-1}\right)$ consistent with regular smoking. Given the inherent problems associated with self-reported information on smoking [38], the present authors elected to use serum cotinine levels as a surrogate for cigarette smoke exposure in the remainder of the analysis. 


\section{FeNO in subjects with elevated serum cotinine levels}

FeNO levels were compared in subjects with serum cotinine levels $<1 \mathrm{ng} \cdot \mathrm{mL}^{-1}$ (subjects with minimal cigarette-smoke exposure), $1-25 \mathrm{ng} \cdot \mathrm{mL}^{-1}$ (subjects with moderate cigarettesmoke exposure consistent with second hand-smoke exposure or occasional smoking) and $\geqslant 25 \mathrm{ng} \cdot \mathrm{mL}^{-1}$ (subjects with high cigarette-smoke exposure and consistent with regular cigarette smoking). FeNO levels were significantly lower only in subjects with serum cotinine levels $\geqslant 25 \mathrm{ng} \cdot \mathrm{mL}^{-1}$ (fig. 1 ). Based on the results in figure 1, subjects were dichotomised into smokers and nonsmokers for all further analyses using a cotinine concentration of $25 \mathrm{ng} \cdot \mathrm{mL}^{-1}$ as a cut-off for the two subject groups.

Consistent with prior studies [1-8], it was found that FeNO levels were significantly lower in smokers compared with nonsmokers (geometric mean $\pm \mathrm{SD}$ ): $13.9 \pm 18.0 \mathrm{ppb}$ versus $20.5 \pm 21.3 \mathrm{ppb}$ $(\mathrm{p}<0.0001)$; difference $=6.6 \mathrm{ppb}$ (confidence interval $(\mathrm{CI}) 4.1-$ 9.2). As shown in figure 2, there was an association of FeNO levels with serum cotinine levels in smokers; serum cotinine levels were inversely correlated with FeNO levels in smokers $\left(\mathrm{r}^{2}=0.13 ; \mathrm{p}=0.0003\right)$, suggesting that lower FeNO levels were associated with increased levels of tobacco smoke exposure.

\section{Age-related declines in FeNO levels in smokers}

The effect of age on FeNO levels was examined in the present cohort. Consistent with prior studies [31], no correlation of age with FeNO levels in nonsmokers was found (fig. 3a). In contrast, analysis of the relationship between FeNO and age in smokers indicated that there was a significant decrease in

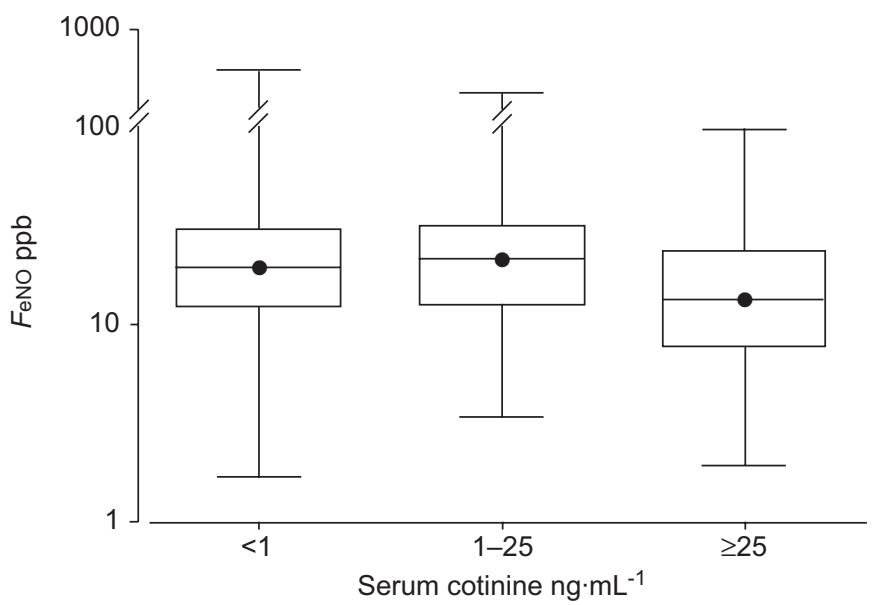

FIGURE 1. Box plot comparison of exhaled nitric oxide fraction ( $F$ eNO) levels from subjects with serum cotinine levels $<1 \mathrm{ng} \cdot \mathrm{mL}^{-1}(\mathrm{n}=770), 1-25 \mathrm{ng} \cdot \mathrm{mL}^{-1}(\mathrm{n}=126)$ and $\geqslant 25 \mathrm{ng} \cdot \mathrm{mL}^{-1}(\mathrm{n}=99)$. FeNO levels were log normalised and compared using ANOVA $(p<0.0001)$. Pairwise comparisons were performed with Tukey-Kramer tests and revealed significant differences between subjects with cotinine levels $\geqslant 25 \mathrm{ng} \cdot \mathrm{mL}^{-1}$ and subjects with cotinine levels $<1 \mathrm{ng} \cdot \mathrm{mL}^{-1}(\mathrm{p}<0.0001)$ and with cotinine levels between $1-25 \mathrm{ng} \cdot \mathrm{mL}^{-1}(p<0.0001)$. A pairwise comparison between subjects with cotinine levels $<1 \mathrm{ng} \cdot \mathrm{mL}^{-1}$ and subjects with cotinine levels between 1 $25 \mathrm{ng} \cdot \mathrm{mL}^{-1}$ was not significant $(\mathrm{p}>0.05)$. The lower and upper limits of the rectangular box plots represent the 25th and 75th percentiles, respectively, for the data in each set. The upper and lower limits of the whisker represent the entire range of the dataset. The horizontal line in the centre of each box plot represents the median for that dataset.

: geometric mean for each dataset.
FeNO levels in older smokers (fig. 3b). A multiple linear regression model confirmed that age was significantly associated with FeNO levels in smokers while controlling for cotinine levels (table 1).

In analyses stratified for age (based on the median age of the cohort, $20 \mathrm{yrs}$ ), comparison of FeNO levels in younger subjects (18-20 yrs) did not reveal significant differences in FeNO levels between smokers and nonsmokers, while FeNO levels in older subjects (21-40 yrs) were significantly different between smokers and nonsmokers ( $\mathrm{p}<0.0001$; fig. 4). Among all subjects, the agerelated difference in FeNO levels between smokers and nonsmokers (i.e. the difference between 18-20-yr-old smokers and nonsmokers compared with the difference between 21-40-yr-old smokers and nonsmokers) was significantly different $(\mathrm{p}<0.0001$; fig. 4) [39].

As there was an uneven distribution of subjects in each age group with regard to the variables listed in table 2, the present authors also tested whether smoking status was significantly associated with FeNO levels in multiple linear regression models when subjects were stratified on the basis of age and while controlling for other variables (sex and total IgE levels; cotinine was not included because it is absent in most nonsmokers) associated with FeNO levels [31, 40]. This analysis confirmed that smoking status was significantly associated with FeNO levels in older subjects (aged 21-40 yrs, $\mathrm{p}<0.0001$; table 3) but not younger subjects (aged 18-20 yrs, $p=0.16$; table 4). Likewise, when smoking status was included in a multiple linear regression model with age, sex and total $\operatorname{IgE}$ levels, there was a significant interaction of age and smoking status ( $p=0.0008$, data not shown).

\section{DISCUSSION}

The current authors believe that their study represents the largest analysis to date of the effect of smoking on FeNO levels in otherwise healthy smokers. The study confirms previous

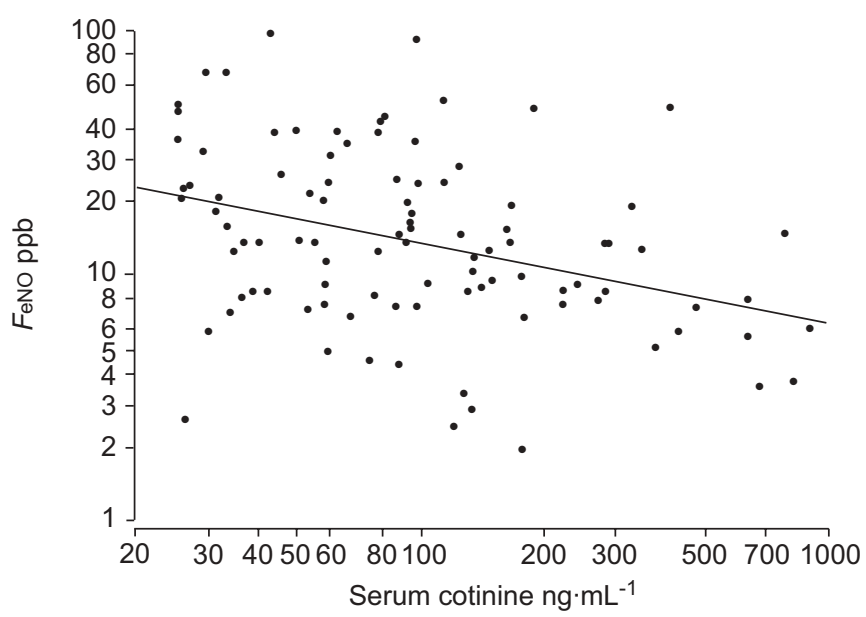

FIGURE 2. Plot of exhaled nitric oxide fraction ( $F$ eNO) levels compared with serum cotinine levels in 99 smokers. FeNO levels and serum cotinine levels were log normalised prior to analysis. Linear regression and Pearson's product-moment correlation coefficient were used to examine the relationship between FeNO levels and serum cotinine levels. —_ derived from the linear regression analysis. $r^{2}=0.13, p=0.0003$. 

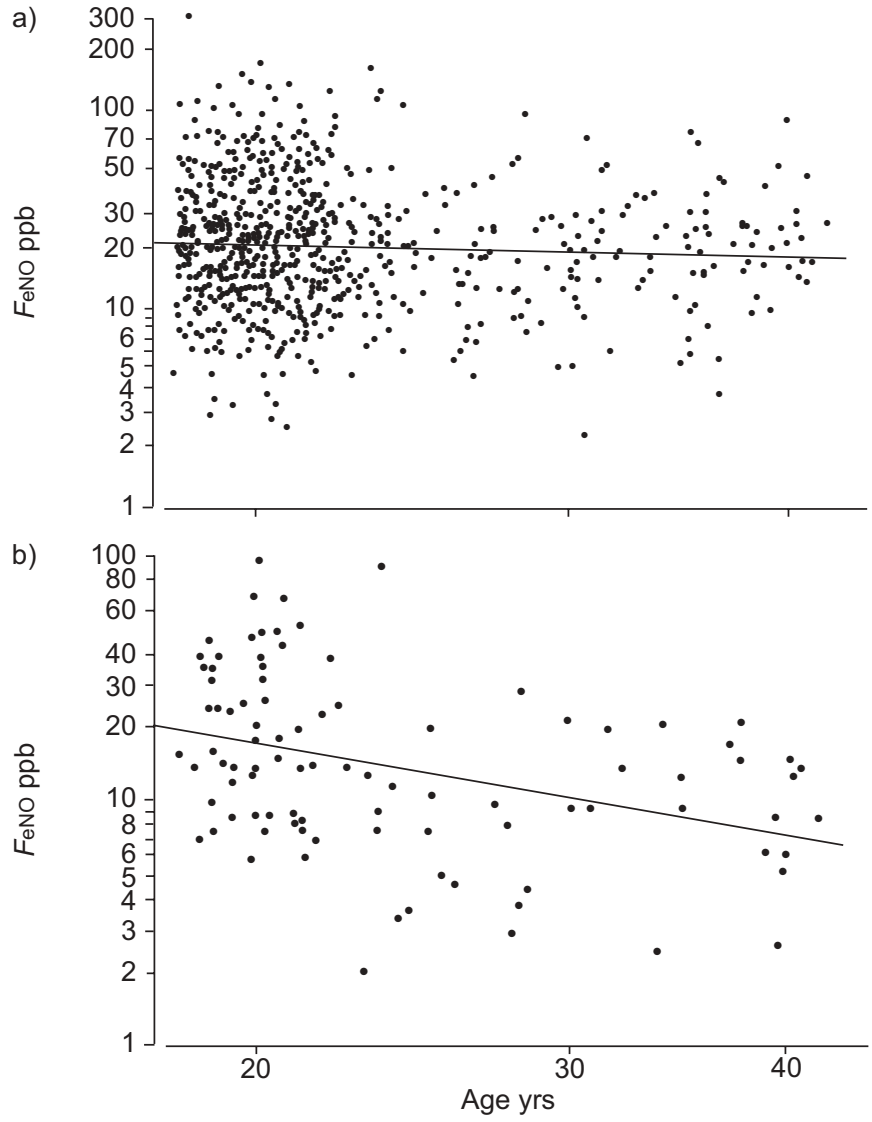

FIGURE 3. Plots of exhaled nitric oxide fraction ( $\mathrm{FeNO}$ ) levels compared with age in a) 98 African-American smokers and b) 876 African-American nonsmokers. FeNO levels and age were log normalised prior to analysis. Linear regression and Pearson's product-moment correlation coefficient were used to examine the relationship between $F_{e N O}$ levels and age. a) $r^{2}<0.01, p=$ nonsignificant; b) $r^{2}=0.15, p=0.0001 ;-$ : derived from the linear regression analyses.

findings indicating that cigarette smoking was associated with lower FeNO levels [1-8] and that greater short-term (hours to days) exposure to inhaled tobacco smoke was associated with greater decreases in FeNO levels (fig. 2) [1]. The current study also addressed the hypothesis that smoking was associated with age-related declines in FeNO. Support for this hypothesis was demonstrated in two ways. First, an age-related decline in FeNO levels in smokers but not nonsmokers was demonstrated (fig. 3). Secondly, it was demonstrated that FeNO levels in older (21-40 yrs of age) smokers but not younger (18-20 yrs of age) smokers were significantly different from comparably aged nonsmokers (fig. 4).

Recent studies by MCSHARRY et al. [32] and MALINOVSCHI et al. [10] did not observe a similar age-related decline in FeNO levels in healthy nonasthmatic smokers. The current authors believe that the present results were different from the results of the other two other studies because they had smaller sample sizes and did not include subjects $<21$ yrs of age. For example, had the present study only analysed the correlation between age and FeNO in the subset of 54 smokers in the cohort aged $>21$ yrs, a correlation between age and FeNO levels would not have been observed $\left(r^{2}=0.0223, p=0.2809\right)$. However, given the

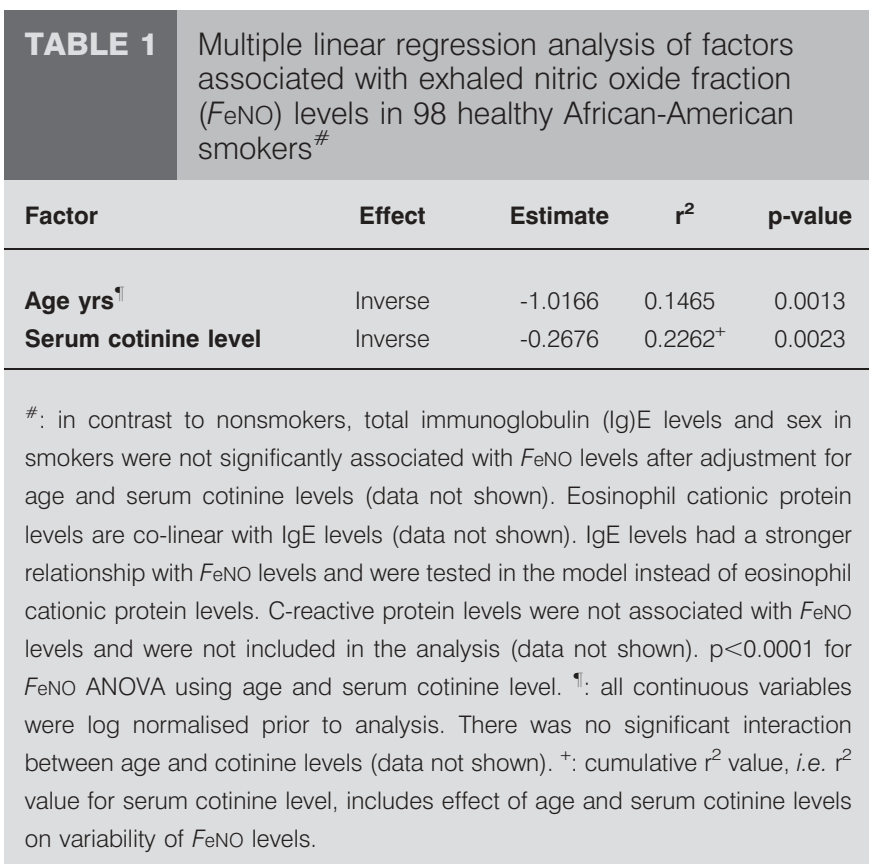

limited numbers of subjects in the current study who were in their late 30's, it remains possible that the analysis in figure $3 a$ was unduly affected by low FeNO levels in some of the oldest smokers in the cohort.

Like the studies of MCSHARry et al. [32] and MALINOvSCHI et al. [10], other studies of smoking and FeNO have not included
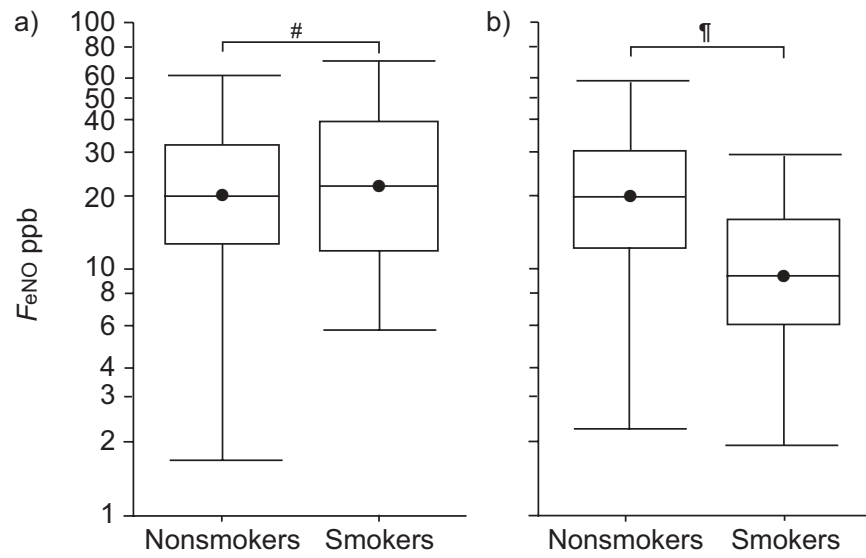

FIGURE 4. Box plot comparison of exhaled nitric oxide fraction ( $F \mathrm{eNO}$ ) levels from African-American subjects with serum cotinine levels $<25 \mathrm{ng} \cdot \mathrm{mL}^{-1}$ (nonsmokers) and $\geqslant 25 \mathrm{ng} \cdot \mathrm{mL}^{-1}$ (smokers) in a) subjects aged 18-20 yrs (515 and 44 subjects, respectively) and b) subjects aged 21-40 yrs (363 and 54 subjects, respectively). FenO levels were log normalised and compared using an unpaired t-test (comparison of $F$ eNO levels for nonsmokers versus smokers was $p=0.9404$ and $p<0.0001$ in $a$ and $b$, respectively). The age-related difference in FeNO levels between smokers and nonsmokers was $p<0.0001$. The lower and upper limits of the box plots represent the 25th and 75th percentiles, respectively, for the data in each set. The upper and lower limits of the whisker plots represent the upper and lower quartiles \pm 1.5 times the interquartile range, respectively, in each dataset. The horizontal line in the centre of each box plot represents the median for that dataset. - : geometric mean for each dataset. ${ }^{\#}: p=$ nonsignificant; " $p<0.0001$. 
TABLE 2 Demographic characteristics and serum concentrations of inflammatory markers and cotinine levels of subjects $\#$

\begin{tabular}{|c|c|c|c|c|}
\hline \multirow[t]{2}{*}{ Factor } & \multirow[t]{2}{*}{ All } & \multicolumn{2}{|c|}{ Age yrs } & \multirow[t]{2}{*}{ p-value } \\
\hline & & $18-20$ & $21-40$ & \\
\hline Sex female/male & $651(66) / 338(34)$ & $372(68) / 179$ (32) & $269(64) / 152(36)$ & 0.2461 \\
\hline Nonsmoker/smoker & $900(90) / 99(10)$ & $518(92) / 44(8)$ & $365(87) / 54(13)$ & 0.0098 \\
\hline Serum total IgE $\mathrm{kU} \cdot \mathrm{L}^{-1}$ & $61 \pm 200$ & $67 \pm 230$ & $57 \pm 170$ & 0.0821 \\
\hline
\end{tabular}

Data are presented as $n(\%)$ or geometric mean \pm SD. Complete information on all subjects was not available. The numbers in the chart represent the numbers of subjects with each characteristic where complete information was available. Dichotomous variables were compared using two-tailed Fisher's exact test. Continuous variables were log normalised and compared using unpaired t-tests. Ig: immunoglobulin. " : in total, 994 subjects were enrolled in the study; ": comparisons between 18-20-yr-olds and 21-40-yr-olds; + : among subjects with serum cotinine concentrations $\geqslant 25 \mathrm{ng} \cdot \mathrm{mL}^{-1}$.

subjects aged $<21$ yrs and, therefore, would not have reached the same conclusions as the present study regarding FeNO levels in young smokers compared with nonsmokers $[1-4,6]$. One possible explanation for the current findings regarding the lack of a difference in FeNO levels in young smokers compared with nonsmokers is related to the known association of increasing age in children (but not adults) with increasing FeNO [40-42]. As such, continued increases in FeNO in adults $<21$ yrs of age may have counteracted smoking-related declines in $\mathrm{FeNO}$ in this age group and accounted for the findings regarding the lack of a difference in $F$ eNO levels in young smokers compared with nonsmokers.

Long-term smoking leads to functional and structural changes in the lung. The present results on the age-related decline in FeNO suggest that the duration of tobacco-smoke exposure might be associated with decreased FeNO levels. The current data does not include self-reported information on the length of time that subjects smoked, although $>80 \%$ of adult smokers start smoking before the age of 18 yrs [43], suggesting that subject age is a reasonable correlate of duration of tobaccosmoke exposure. While other factors besides smoking may account for the age-related decline in FeNO levels in smokers, the present authors believe this is unlikely because there were no age-related changes in FeNO levels in nonsmokers (fig. 3a).

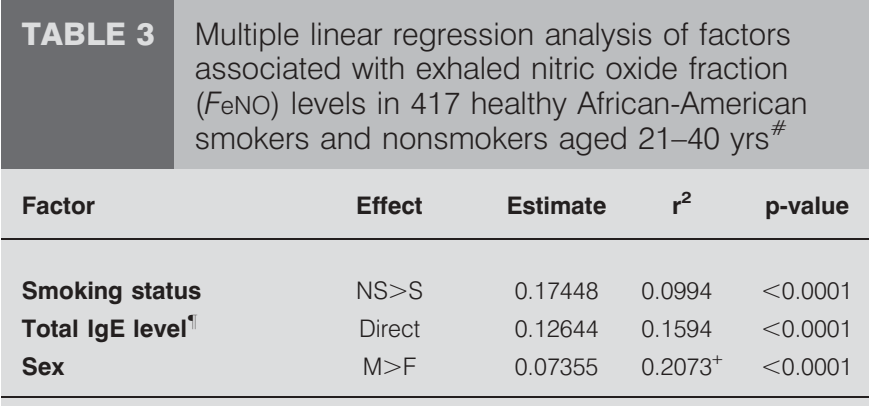

Ig: immunoglobulin; NS: nonsmoker; S: smoker; $\mathrm{M}$ : male; F: female. \#: $p<0.0001$ for FeNO ANOVA using smoking status, sex and total IgE levels; ': all continuous variables were log normalised prior to analysis; ${ }^{+}$: cumulative $r^{2}$ value, i.e. $r^{2}$ value for sex, includes effect of smoking status, total lgE and sex on variability of $F$ eNO levels.
The presence of mild chronic obstructive pulmonary disease (COPD) in older subjects may have influenced the results. Although RoY et al. [44] recently found that COPD was associated with decreased airway NO levels, most studies suggest that COPD is associated with increased FeNO levels [4, $45]$ and, if anything, this would have diminished the difference in FeNO levels between older smokers and nonsmokers. Taken together, the current authors believe that long-term smoking may result in permanent reductions in FeNO levels, possibly via airway epithelial lining changes and changes in NOS2 expression and NO production.

Tobacco-smoke exposure is associated with airway epithelial hyperplasia, mucus cell hyperplasia, airway metaplasia, epithelial damage and airway neutrophil infiltration [16, 17]. Many of these changes persist after subjects quit smoking, including persistence of neutrophil inflammation $[16,17]$. The hypothesis that long-term cigarette smoking is associated with permanent reductions in FeNO is supported by studies on older smokers who quit smoking $[2,6]$. While these studies indicated that $F$ eNO levels increased in subjects after they quit smoking, former smokers still had lower FeNO levels compared with healthy control subjects [2, 6]. Likewise, MALINOvsCHI et al. [10] found that ex-smokers had significantly lower FeNO levels than never-smokers. A prospective, longitudinal study of abstaining smokers who had previously smoked cigarettes for various

TABLE 4 Multiple linear regression analysis of factors associated with exhaled nitric oxide fraction ( $(\mathrm{eNO})$ levels in 559 healthy African-American smokers and nonsmokers aged $18-20 \mathrm{yrs}^{\#}$

\begin{tabular}{lcccc} 
Factor & Effect & Estimate & $\mathbf{r}^{2}$ & $\mathbf{p}$-value \\
\hline Total IgE level & Direct & 0.16198 & 0.1231 & $\mathrm{p}<0.0001$ \\
Sex & $M>F$ & 0.07143 & $0.1662^{\circ}$ & $p<0.0001$ \\
\hline
\end{tabular}

All continuous variables were log normalised prior to analysis. When added to the model, the $\mathrm{p}$-value for smoking status as an individual variable was 0.1654. Ig: immunoglobulin; M: male; F: female. ${ }^{*}:$ p $<0.0001$ for FeNO ANOVA using sex and total IgE levels; ' effect of total lgE levels and sex on variability of $F$ eNO levels. 
durations would provide better evidence to support the hypothesis that long-term smoking may be associated with permanent reductions in FeNO levels.

The design of the present study did not allow direct examination of respiratory epithelium in smokers or the correlation of epithelial damage with FeNO. Therefore, other hypotheses that account for the age-related decline in FeNO in smokers are also possible. Smoking-related downregulation of epithelial NOS2 enzyme activity and smoking-related increases in airway enzymes and reactive oxygen species that react with or metabolise $\mathrm{NO}$ are possible aetiologies for the age-related decline in FeNO in smokers [10, 46]. Another hypothesis relates smoking-induced pulmonary changes due to COPD as the cause of decreased FeNO in smokers. As stated earlier, while most studies found that FeNO levels increase in patients with COPD [4, 45], more recent data from RoY et al. [44], using multiple measurements of exhaled $\mathrm{NO}$ at different flow rates to model airway NO, suggests that FeNO levels are lower in COPD patients. Like the hypothesis about smokingrelated respiratory epithelial damage, the COPD hypothesis would associate COPD-related inflammatory changes and parenchymal lung damage with reductions in FeNO. Although the current results do not provide definitive evidence to address these hypotheses as the cause of decreased FeNO levels in smokers, the results of the present study clearly support an association of an age-related decline in FeNO in smokers.

While the present authors focused on the possibility that smoking has significant age-related effects on airway respiratory epithelium, it is possible that other compartments within the lung may contribute to the lower FeNO levels associated with smoking. All three isoforms of NOS are expressed in the lung [11]. Techniques that permit separate measurement of the airway and alveolar components of FeNO would be useful in this context to address the hypothesis that smoking primarily alters airway respiratory epithelial production of FeNO [47]. Experiments using intravenous and inhaled inhibitors of the different isoforms of NOS would also be useful to delineate the relative contributions of neural NOS1, airway NOS2 and vascular NOS3 to the difference in FeNO between older smokers and nonsmokers [15, 48].

Measurement of serum cotinine, a nicotine metabolite, is an objective surrogate for quantifying tobacco-smoke exposure [49]. Cotinine levels can be accurately measured in blood, urine, saliva and other body fluids. The half-life of cotinine in serum is $15-17 \mathrm{~h}$, which allows for accurate estimation of daily tobacco-smoke exposure in randomly obtained blood specimens [49]. Serum cotinine levels correlate well with the number of cigarettes smoked and with the amount of time since a cigarette was smoked [50-52]. Information on the number of cigarettes that subjects smoked was not collected in the current study and, as such, relied on the use of serum cotinine levels as a surrogate marker of cigarette consumption.

The present authors believe that serum cotinine levels represent the best available assessment of smoking status in the cohort as subject self-reports of smoking habits did not adequately exclude smokers. Based on data provided by the manufacturer of the cotinine assay and published studies [53], it is believed that the manufacturer-recommended cut-off of $25 \mathrm{ng} \cdot \mathrm{mL}^{-1}$ for serum cotinine levels is conservative and unlikely to include many nonsmoking subjects exposed to passive smoke. The significantly lower FeNO levels in subjects with serum cotinine levels $\geqslant 25 \mathrm{ng} \cdot \mathrm{mL}^{-1}$ (fig. 2) and the comparable FeNO levels in current smokers versus subjects with serum cotinine levels $\geqslant 25 \mathrm{ng} \cdot \mathrm{mL}^{-1}$ also supports the rationale for selecting $25 \mathrm{ng} \cdot \mathrm{mL}^{1}$ as a cut-off for classification of smoking status. The current data did not indicate lower FeNO levels in subjects with cotinine levels between 1-25 $\mathrm{ng} \cdot \mathrm{mL}^{-1}$ and there was only a weak correlation between $\mathrm{FeNO}$ and serum cotinine levels in subjects with cotinine levels between $1-25 \mathrm{ng} \cdot \mathrm{mL}^{-1}\left(\mathrm{r}^{2}=0.03, \mathrm{p}=0.0410\right)$. Furthermore, serum cotinine concentrations $>1 \mathrm{ng} \cdot \mathrm{mL}^{-1}$ and $<25 \mathrm{ng} \cdot \mathrm{mL}^{-1}$ are consistent with exposure to second-hand smoke [53]. In contrast to the declines in FeNO associated with cigarette smoking, a recent publication found that exposure to secondhand smoke was associated with modestly increased FeNO levels [53]. Taken together with the present data on the relationship of FeNO levels and serum cotinine levels (fig. 2), the current authors believe that this data supports dichotimisation of subjects into smokers and nonsmokers on the basis of a serum cotinine level of $25 \mathrm{ng} \cdot \mathrm{mL}^{-1}$.

In summary, the present results indicated that smoking had different impacts on exhaled nitric oxide levels in subgroups of otherwise healthy smokers. Smoking-related declines in exhaled nitric oxide levels appeared to be disproportionately greater in older individuals. This suggested that smoking was associated with age-related declines in exhaled nitric oxide and justifies future mechanistic studies that address the impact of exhaled nitric oxide fraction decline on lung function.

\section{ACKNOWLEDGEMENTS}

The authors are grateful for the assistance of E. Scarlett and C. Foss during subject enrolment and sample collection. They also acknowledge C. Thomas and C. Tao for assistance with computer data entry. The use of J.B. Weinberg's nitric oxide analyser and W. Burks' (all affiliated with Duke University Medical Center, Durham, NC, USA) CAP-FEIA instrument for measurement of exhaled nitric oxide levels and total IgE levels, respectively, was greatly appreciated.

\section{REFERENCES}

1 Kharitonov SA, Robbins RA, Yates D, Keatings V, Barnes PJ. Acute and chronic effects of cigarette smoking on exhaled nitric oxide. Am J Respir Crit Care Med 1995; 152: 609-612.

2 Robbins RA, Millatmal T, Lassi K, Rennard S, Daughton D. Smoking cessation is associated with an increase in exhaled nitric oxide. Chest 1997; 112: 313-318.

3 Verleden GM, Dupont LJ, Verpeut AC, Demedts MG. The effect of cigarette smoking on exhaled nitric oxide in mild steroid-naive asthmatics. Chest 1999; 116: 59-64.

4 Corradi M, Majori M, Cacciani GC, Consigli GF, de'Munari E, Pesci A. Increased exhaled nitric oxide in patients with stable chronic obstructive pulmonary disease. Thorax 1999; 54: 572-575.

5 Yates DH, Breen H, Thomas PS. Passive smoke inhalation decreases exhaled nitric oxide in normal subjects. Am J Respir Crit Care Med 2001; 164: 1043-1046. 
6 Hogman M, Holmkvist T, Walinder R, et al. Increased nitric oxide elimination from the airways after smoking cessation. Clin Sci 2002; 103: 15-19.

7 Warke TJ, Mairs V, Fitch PS, Ennis M, Shields MD. Possible association between passive smoking and lower exhaled nitric oxide in asthmatic children. Arch Environ Health 2003; 58: 613-616.

8 Horvath I, Donnelly LE, Kiss A, Balint B, Kharitonov SA, Barnes PJ. Exhaled nitric oxide and hydrogen peroxide concentrations in asthmatic smokers. Respiration 2004; 71: 463-468.

9 Maniscalco M, Di Mauro V, Farinaro E, Carratu L, Sofia M. Transient decrease of exhaled nitric oxide after acute exposure to passive smoke in healthy subjects. Arch Environ Health 2002; 57: 437-440.

10 Malinovschi A, Janson C, Holmkvist T, Norback D, Merilainen P, Hogman M. Effect of smoking on exhaled nitric oxide and flow-independent nitric oxide exchange parameters. Eur Respir J 2006; 28: 339-345.

11 Kobzik L, Bredt DS, Lowenstein CJ, et al. Nitric oxide synthase in human and rat lung: immunocytochemical and histochemical localization. Am J Respir Cell Mol Biol 1993; 9: 371-377.

12 Asano K, Chee CB, Gaston B, et al. Constitutive and inducible nitric oxide synthase gene expression, regulation, and activity in human lung epithelial cells. Proc Nat Acad Sci USA 1994; 91: 10089-10093.

13 Guo FH, Uetani K, Haque SJ, et al. Interferon- $\gamma$ and interleukin 4 stimulate prolonged expression of inducible nitric oxide synthase in human airway epithelium through synthesis of soluble mediators. J Clin Invest 1997; 100: 829-838.

14 Sapienza MA, Kharitonov SA, Horvath I, Chung KF, Barnes PJ. Effect of inhaled L-arginine on exhaled nitric oxide in normal and asthmatic subjects. Thorax 1998; 53: 172-175.

15 Yates DH, Kharitonov SA, Thomas PS, Barnes PJ. Endogenous nitric oxide is decreased in asthmatic patients by an inhibitor of inducible nitric oxide synthase. Am J Respir Crit Care Med 1996; 154: 247-250.

16 Dye JA, Adler KB. Effects of cigarette smoke on epithelial cells of the respiratory tract. Thorax 1994; 49: 825-834.

17 Wright JL, Hobson JE, Wiggs B, Pare PD, Hogg JC. Airway inflammation and peribronchiolar attachments in the lungs of nonsmokers, current and ex-smokers. Lung 1988; 166: 277-286.

18 Wistuba II, Mao L, Gazdar AF. Smoking molecular damage in bronchial epithelium. Oncogene 2002; 21: 7298-7306.

19 Yokohori N, Aoshiba K, Nagai A, Respiratory Failure Research Group in Japan. Increased levels of cell death and proliferation in alveolar wall cells in patients with pulmonary emphysema. Chest 2004; 125: 626-632.

20 Hodge S, Hodge G, Holmes M, Reynolds PN. Increased airway epithelial and T-cell apoptosis in COPD remains despite smoking cessation. Eur Respir J 2005; 25: 447-454.

21 Tager IB, Segal MR, Speizer FE, Weiss ST. The natural history of forced expiratory volumes. Effect of cigarette smoking and respiratory symptoms. Am Rev Respir Dis 1988; 138: 837-849.

$22 \mathrm{Xu} \mathrm{X}$, Dockery DW, Ware JH, Speizer FE, Ferris BG Jr. Effects of cigarette smoking on rate of loss of pulmonary function in adults: a longitudinal assessment. Am Rev Respir Dis 1992; 146: 1345-1348.

23 Peat JK, Woolcock AJ, Cullen K. Decline of lung function and development of chronic airflow limitation: a longitudinal study of non-smokers and smokers in Busselton, Western Australia. Thorax 1990; 45: 32-37.

24 James AL, Palmer LJ, Kicic E, et al. Decline in lung function in the Busselton Health Study: the effects of asthma and cigarette smoking. Am J Respir Crit Care Med 2005; 171: 109-114.

25 Dupuy PM, Shore SA, Drazen JM, Frostell C, Hill WA, Zapol WM. Bronchodilator action of inhaled nitric oxide in guinea pigs. J Clin Invest 1992; 90: 421-428.

26 Persson MG, Friberg SG, Hedqvist P, Gustafsson LE. Endogenous nitric oxide counteracts antigen-induced bronchoconstriction. Eur J Pharma 1993; 249: R7-R8.

27 Hogman M, Frostell CG, Hedenstrom H, Hedenstierna G. Inhalation of nitric oxide modulates adult human bronchial tone. Am Rev Respir Dis 1993; 148: 1474-1478.

28 Que LG, Liu L, Yan Y, et al. Protection from experimental asthma by an endogenous bronchodilator. Science 2005; 308: 1618-1621.

29 Fang FC. Perspectives series: host/pathogen interactions. Mechanisms of nitric oxide-related antimicrobial activity. J Clin Invest 1997; 99: 2818-2825.

30 Nathan C. Inducible nitric oxide synthase: what difference does it make? J Clin Invest 1997; 100: 2417-2423.

31 Tsang KW, Ip SK, Leung R, et al. Exhaled nitric oxide: the effects of age, gender and body size. Lung 2001; 179: 83-91.

32 McSharry CP, McKay IC, Chaudhuri R, Livingston E, Fraser I, Thomson NC. Short and long-term effects of cigarette smoking independently influence exhaled nitric oxide concentration in asthma. J Allergy Clin Immunol 2005; 116: 88-93.

33 Levesque MC, Hauswirth DW, Mervin-Blake S, et al. Determinants of exhaled nitric oxide levels in healthy non-smoking African American adults. I Allergy Clin Immunol 2007; (in press).

34 Ferris BG. Epidemiology Standardization Project (American Thoracic Society). Am Rev Respir Dis 1978; 118: 1-120.

35 Silkoff PE. Recommendations for standardized procedures for the on-line and off-line measurement of exhaled lower respiratory nitric oxide and nasal nitric oxide in adults and children-1999. This official statement of the American Thoracic Society was adopted by the ATS Board of Directors, July 1999. Am J Respir Crit Care Med 1999; 160: 2104-2117.

36 van Vunakis $H$, Tashkin DP, Rigas B, Simmons $M$, Gjika HB, Clark VA. Relative sensitivity and specificity of salivary and serum cotinine in identifying tobacco-smoking status of self-reported nonsmokers and smokers of tobacco and/or marijuana. Arch Environ Health 1989; 44: 53-58.

37 Matsukura S, Taminato $\mathrm{T}$, Kitano N, et al. Effects of environmental tobacco smoke on urinary cotinine excretion in nonsmokers. Evidence for passive smoking. $N$ Engl J Med 1984; 311: 828-832.

38 Patrick DL, Cheadle A, Thompson DC, Diehr P, Koepsell T, Kinne S. The validity of self-reported smoking: a review and meta-analysis. Am J Public Health 1994; 84: 1086-1093. 
39 Matthews JN, Altman DG. Interaction 3: How to examine heterogeneity. BMJ 1996; 313: 5.

40 Strunk RC, Szefler SJ, Phillips BR, et al. Relationship of exhaled nitric oxide to clinical and inflammatory markers of persistent asthma in children. J Allergy Clin Immunol 2003; 112: 883-892.

41 Franklin PJ, Taplin R, Stick SM. A community study of exhaled nitric oxide in healthy children. Am J Respir Crit Care Med 1999; 159: 69-73.

42 Buchvald F, Baraldi E, Carraro S, et al. Measurements of exhaled nitric oxide in healthy subjects age 4 to 17 years. J Allergy Clin Immunol 2005; 115: 1130-1136.

43 Services DoHaH. Preventing Tobacco Use Among Young People: A Report of the Surgeon General. Washington, Government Printing Office, 1994; p. 65.

44 Roy K, Borrill ZL, Starkey C, et al. Use of different exhaled nitric oxide multiple flow rate models in COPD. Eur Respir J 2007; 29: 651-659.

45 Maziak W, Loukides S, Culpitt S, Sullivan P, Kharitonov SA, Barnes PJ. Exhaled nitric oxide in chronic obstructive pulmonary disease. Am J Respir Crit Care Med 1998; 157: 998-1002.

46 Ricciardolo FL, Caramori G, Ito K, et al. Nitrosative stress in the bronchial mucosa of severe chronic obstructive pulmonary disease. J Allergy Clin Immunol 2005; 116: 1028-1035.
47 Shin HW, Shelley DA, Henderson EM, Fitzpatrick A, Gaston B, George SC. Airway nitric oxide release is reduced after PBS inhalation in asthma. J App Physiol 2007; 102: 1028-1033.

48 Ricciardolo FL, Geppetti P, Mistretta A, et al. Randomised double-blind placebo-controlled study of the effect of inhibition of nitric oxide synthesis in bradykinin-induced asthma. Lancet 1996; 348: 374-377.

49 Tricker AR. Nicotine metabolism, human drug metabolism polymorphisms, and smoking behaviour. Toxicology 2003; 183: 151-173.

50 Yang M, Kunugita N, Kitagawa K, et al. Individual differences in urinary cotinine levels in Japanese smokers: relation to genetic polymorphism of drug-metabolizing enzymes. Cancer Epidemiol Biomarkers Prev 2001; 10: 589-593.

51 McDonald SD, Perkins SL, Walker MC. Correlation between self-reported smoking status and serum cotinine during pregnancy. Addic Behav 2005; 30: 853-857.

52 Berlin I, Radzius A, Henningfield JE, Moolchan ET. Correlates of expired air carbon monoxide: effect of ethnicity and relationship with saliva cotinine and nicotine. Nicotine Tob Res 2001; 3: 325-331.

53 Menzies D, Nair A, Williamson PA, et al. Respiratory symptoms, pulmonary function, and markers of inflammation among bar workers before and after a legislative ban on smoking in public places. JAMA 2006; 296: 1742-1748. 